\title{
EXPERIMENTAL STUDY OF THE FLEXURAL WAVES IN THE FRACTURED OR CASED BOREHOLE MODEL
}

\author{
by \\ Zhenya Zhu, C.H. Cheng, and M.N. Toksöz \\ Earth Resources Laboratory \\ Department of Earth, Atmospheric, and Planetary Sciences \\ Massachusetts Institute of Technology \\ Cambridge, MA 02139
}

\begin{abstract}
The ultrasonic logging is performed with dipole transducers in aluminum and lucite borehole models to study the propagation of the flexural waves in a fractured or cased borehole. The experimental results show that the flexural wave is much more sensitive to a horizontal fracture than to a vertical one. The propagation of flexural waves in a borehole with an inclined fracture is related to both the polarization of the flexural wave and the direction of the fracture. The experimental results show that a very strong low-frequency flexural wave can be generated by a dipole source in a cased borehole and it propagates with the shear wave velocity of the formation. High-frequency waves generated by a dipole source propagate with the compressional wave and flexural wave velocities of the casing. Dipole acoustic well logging could be an effective means for determining horizontal and declined fractures and measuring the formation shear wave velocity in a cased borehole.
\end{abstract}

\section{INTRODUCTION}

Exploration of a fracture is very important for the evaluation of petroleum geology. The growth of fractures is related to the moving of petroleum in a formation. Since the full waveform acoustic well logging was developed, the propagation of the monopole waves in an open fractured borehole, particularly the Stoneley wave propagation across a fracture, has been studied (Paillet, 1980; Tang et al., 1991a,b). Theoretical study shows that the reflection and transmission of Stoneley waves are generated at a fluidfilled fracture, and very strong reflection and attenuation of low-frequency Stoneley wave are observed at a vertical fracture. The compressional wave of the full waveform log is not sensitive to a fracture. The shear wave should be sensitive to a fracture, but it is difficult to determine the attenuation of the shear wave because of interference by the leaking mode and the pseudo-Rayleigh wave.

The monopole acoustic wave in a cased borehole is shielded by the casing. Most of the energy, particularly the high-frequency component of the waves, is concentrated in the borehole and formed as a casing wave (Tubman et al., 1984; Block et al., 1991). The 
casing wave is sometimes too strong to extract the compressional and shear waves from the full waveforms. The application of full waveform acoustic well logging in a cased borehole is limited.

The vibration mode of a flexural wave generated by a dipole source is completely different from that by a monopole source (Kurkjian, 1986; Schmitt et al., 1988; Zhu et al., 1993). The stresses and particle displacements excited by a dipole source are in the horizontal direction perpendicular to the borehole axis. Therefore the flexural wave is sensitive to the discontinuation of the formation along the axis. Because of the polarization of the flexural wave, its propagation is affected by the direction of a fracture. In our study, the effects of horizontal, vertical and inclined fractures on the propagation of the flexural waves are studied using aluminum and lucite models.

Theoretical study and field measurements (Chen and Eriksen, 1991; Winbow, 1991) show that a low-frequency flexural wave in a cased borehole propagates with the shear velocity of the formation. In our study, the propagation of the flexural waves at different frequencies is studied with the aluminum and lucite cased borehole models. The results show that the most important parameter is the frequency of the flexural wave. Only at very low frequency, the velocity of the flexural wave is equal to the shear wave velocity of the formation.

\section{DIPOLE TRANSDUCER AND BOREHOLE MODEL}

To generate purer flexural waves in a scaled model borehole than is observed in a previous attempt (Zhu et al., 1993 Annual Report), the dipole source and receiver are made of PZT piezoelectric thin plates vibrating in a bending mode. The construction is shown in Figure 1.

Two PZT plates with the same polarization are glued together. The two electrodes come from outside surfaces and glued surfaces, respectively. The electrodes of the two PZT plates are in parallel connection. The relative directions of the polarizations and the electric fields are opposite for the plates. When the electric field is applied to the transducer, one plate expands, the other contracts and a bending vibration mode is generated. A horizontal displacement is produced in the surrounding fluid. The bending vibration frequency $f_{r}$ is:

$$
f_{r}=N_{1} \beta \frac{t}{3 L^{2}}
$$

where $L$ is the length of the plate, $t$ is the total thickness of the two plates, $N_{1}$ is the frequency constant of the piezoelectric material, $\beta$ is a factor which is related to the surrounding material (when the material is air, $\beta=1$; when it is fluid, $\beta<1$ ).

The dipole transducer we made is $12 \mathrm{~mm}$ in length, $5 \mathrm{~mm}$ in width and $0.6 \mathrm{~mm}$ in thickness. The center frequency is about $100 \mathrm{kHz}$. Besides the bending vibration mode, there is a thickness vibration mode for the transducer. Because the frequency of the thickness vibration mode is about $3 \mathrm{MHz}$, only the bending mode can be generated and 
received at $100 \mathrm{kHz}$. The radiation of the dipole transducer is measured in a water tank by rotating it around the length axis. The waveforms received at different azimuths and the radiation pattern are shown in Figure 2. It is very clear that the phase of the two main lobes in the pattern are of opposite signs. Because of the limitations of the technology for making the transducer, the sizes of the two main lobes are not exactly symmetrical.

To simulate hard and soft formations, five fractured models are made of aluminum and lucite, respectively. They are aluminum models with horizontal, vertical and $45^{\circ}$ inclined fractures, and lucite models with horizontal and vertical fractures. The diameter of the borehole is $10 \mathrm{~mm}$, the fracture is $2 \mathrm{~mm}$ in width. The compressional, shear velocities and density of aluminum and lucite are $6270 \mathrm{~m} / \mathrm{s}, 3080 \mathrm{~m} / \mathrm{s}, 2.7 \mathrm{~g} / \mathrm{cm}^{3}$ and $2550 \mathrm{~m} / \mathrm{s}, 1290 \mathrm{~m} / \mathrm{s}, 1.2 \mathrm{~g} / \mathrm{cm}^{3}$, respectively. The velocities of Stoneley waves in aluminum and lucite model boreholes are $1450 \mathrm{~m} / \mathrm{s}$ and $1020 \mathrm{~m} / \mathrm{s}$, respectively.

\section{MEASUREMENTS IN FRACTURED BOREHOLES}

The measurements with a dipole source and a dipole receiver are performed with five aluminum and lucite fractured models in a water tank. The source transducer is excited by an electric one cycle sine-burst signal. The receiver with same polarization as the source moves along the water-filled borehole and records the received waves with $5 \mathrm{~mm}$ spacing. The center frequency of the input signal is adjustable. To obtain a maximum amplitude, the waveforms are recorded at different frequency ranges because of the different response of the boreholes. The frequency in the aluminum model is higher than that in the lucite model. The following figures show the recorded waveforms in the modeis.

\section{Model with a Horizontal Fracture}

Figure 3 shows the waveforms of flexural wave in aluminum and lucite borehole models with horizontal fractures, respectively. The location of the fracture is shown by an arrow in the figures.

The flexural wave generated by a dipole source propagates along the borehole axis with the shear wave velocity of the formation. After the dipole receiver passes the horizontal fracture, almost no flexural wave can be received. This means that the flexural wave cannot be transferred across the fracture. Because the compressional wave can be propagated in the fluid, the monopole wave can be more effectively transferred across the horizontal fracture. Figure 4 shows the monopole waves in the models with horizontal fractures. From the waverorms, it can be seen that a significant portion of the energy of the compressional wave and Stoneley wave propagates across the horizontal fracture. Comparing Figure 3 and Figure 4, we can know that the monopole wave is not as sensitive to horizontal fracture as the flexural wave. 


\section{Model with a Vertical Fracture}

Figure 5 shows the waveforms received in an aluminum model with a vertical fracture which is parallel (Figure 5a) to or perpendicular (Figure $5 \mathrm{~b}$ ) to the polarization of the dipole transducers. The dipole source is fixed at the borehole section without the vertical fracture. Figure 6 shows the waveforms in the lucite borehole model with a vertical fracture.

From these plots, it is difficult to see any large change of the waveforms when the dipole receiver moves from the section without fracture to that with fracture. However, it is still possible to observed that the flexural wave does attenuate in a vertical fracture, more so when the dipole is aligned with the fracture direction. This means that the flexural wave is only somewhat sensitive to the vertical fracture in a borehole. In contrast, the Stoneley wave is sensitive to vertical fractures (Tang et al., 1991a)

From the radiation pattern of the dipole transducer which is used in our experiment, we can see that the direction is not very sharp. If the direction of the radiation is sharper and the width of the fracture is larger, the effect of the fracture on the flexural wave will'be larger.

\section{Model with a $45^{\circ}$-inclined Fracture}

Figure 7 shows the waveforms received in an aluminum model with a $45^{\circ}$-inclined fracture whose normal direction is perpendicular to the polarization of the dipole source and receiver (Figure $7 \mathrm{a}$ ) or in the same plane (Figure $7 \mathrm{~b}$ ).

When the polarization of the dipole source and the normal direction of the inclined fracture are in the same plane, the flexural wave cannot pass the fracture (Figure 7b). This is very similar to the model with a horizontal fracture. When the polarization of the dipole is perpendicular to the normal direction of the inclined fracture, it is obvious that a part of the flexural wave can pass the fracture and be received. In this case, the energy of the flexural wave passing the inclined fracture depends on the polarization direction of the wave.

\section{MEASUREMENTS IN A CASED BOREHOLE}

A cased borehole model is shown in Figure 8. A glass pipe with $1 \mathrm{~mm}$ thickness simulates the casing in a borehole. The compressional, shear velocities and the density of the glass are $5570 \mathrm{~m} / \mathrm{s}, 3520 \mathrm{~m} / \mathrm{s}$ and $2.6 \mathrm{~g} / \mathrm{cm}^{3}$, respectively. The glass pipe is cemented in the borehole center with wax. The compressional, shear velocities and the density of the wax are $2400 \mathrm{~m} / \mathrm{s}, 950 \mathrm{~m} / \mathrm{s}$ and $0.9 \mathrm{~g} / \mathrm{cm}^{3}$, respectively. The models are made of aluminum and lucite, respectively.

The same measurements are performed with these cased models. The electric signal for exciting the dipole source is a single sine-burst whose frequency is variable. Figure 9 
shows the waveforms received in the aluminum cased model. The center frequencies are about $70 \mathrm{kHz}$ (Figure 9a) and $250 \mathrm{kHz}$ (Figure 9b), respectively. From these waveforms, we can see that when the center frequency is about $70 \mathrm{kHz}$ the received flexural wave propagates with the shear velocity of the formation (aluminum). When the frequency increases (Figure 9b), the wave propagating with the shear velocity of the formation disappears, and only that propagating with the compressional and flexural velocities of the glass casing can be received. This shows that only at low frequency range the flexural wave with the shear velocity of the formation can be generated. The flexural wave at higher frequencies would be affected and shielded by the casing. This means that the shear velocity of the formation surrounding a cased borehole can be measured by dipole acoustic well logging at low frequency range.

Comparing with Figure 9a, the low-frequency component of the wave generated by a monopole source in the aluminum cased borehole model is recorded in Figure 10. The center frequency is about $80 \mathrm{kHz}$. The velocity is about $1200 \mathrm{~m} / \mathrm{s}$. It is a Stoneley wave generated by a monopole in a cased borehole. It is clear that the low-frequency flexural wave (Figure 9a) is totally different from the Stoneley wave (Figure 10), but it is difficult to distinguish between the shear velocities of the glass and the formation (aluminum) because they are very close.

The same experiments are performed with the lucite cased borehole model. In Figure 11 the waveforms generated by a dipole source at different frequency ranges are recorded. At the $50 \mathrm{kHz}$ frequency range (Figure 11a) the flexural wave propagates with the velocity of $1290 \mathrm{~m} / \mathrm{s}$ which is equal to the shear velocity of lucite and is not the glass shear velocity $(3500 \mathrm{~m} / \mathrm{s})$. When the frequency increases, the amplitude of the wave with lucite shear velocity decreases and the wave with the compressional velocity $(5800 \mathrm{~m} / \mathrm{s})$ is recorded (Figure 11b). At higher frequency, both of the waves disappeared (Figure 11c), and only the flexural wave related to the bending mode of the glass pipe can be recorded. Its velocity is about $1620 \mathrm{~m} / \mathrm{s}$. The low-frequency component generated by a monopole source in the lucite cased model is shown in Figure 12. It is a Stoneley wave.

\section{CONCLUSIONS}

In this study, the flexural waves are generated by a dipole source in the fractured or cased borehole models made of aluminum and lucite, and are compared with those generated by a monopole source, respectively. The results show the following:

1. The flexural wave is very sensitive to a fluid-filled horizontal fracture, but is not sensitive to a vertical fracture. The flexural wave almost cannot pass the horizontal fracture. A vertical fracture does not affect the propagation of the flexural wave. The flexural wave is sensitive to an inclined fracture. The amplitude across an inclined fracture decreases obversely and depends on the relative direction of both the polarization of the dipole source and the direction of the fracture. Because of the direction of a dipole source, the dipole acoustic well logging is useful to determine the strike of an inclined fracture. Most energy of the compressional and Stoneley waves generated by a monopole source can propagate across all kinds of fractures. 
2. The low-frequency flexural wave propagates with the shear velocity in a cased borehole surrounded by the hard or soft formation. The velocity of the formation of the flexural wave at high frequency range is controlled by the casing and the wave is related to the compressional and the flexural waves of the casing. Dipole acoustic well logging should be an effective means for directly measuring the shear velocity of the hard or soft formation in a cased borehole.

\section{ACKNOWLEDGEMENT}

This study is supported by the Borehole Acoustics and Logging Consortium at M.I.T. and by Department of Energy Grant DE-FG02-86ER13636. 


\section{REFERENCES}

Block, L.V., C.H. Cheng, and G.L. Duckworth, 1991, Velocity analysis of multi-receiver full waveform acoustic logging data in open and cased holes, The Log Analyst, 32, 188-200.

Chen, S.T., and A. Eriksen, 1991, Compressional and shear-wave logging in open and cased holes using a multipole tool, Geophysics, 56, 550-557.

Kurkjian, A.L., and S.K. Chang, 1986, Acoustic multipole sources in a fluid-filled borehole, Geophysics, 51, 148-163.

Paillet, F.L., 1980 Acoustic propagation in the vicinity of fractures which intersect a fluid-filled borehole, Trans. 21st SPWLA Ann. Symp., Paper DD.

Schmitt, D.P., Y. Zhu, and C.H. Cheng, 1988, Shear wave logging in semi-infinite saturated porous formation, J.Acoust. Soc. Am., 84(6), 2230-2244.

Tang, X.M., C.H. Cheng, and M.N. Toksöz, 1991a, Stoneley-wave propagation in a fluid-filled borehole with a vertical fracture, Geophysics, 56, 447-460.

Tang, X.M., C.H. Cheng, and F.L. Paillet, 1991b, Modeling Stoneley wave propagation across in-situ fracture, Trans. 36th SPWLA Ann. Symp.

Tubman, K.M., C.H. Cheng, and M.N. Toksöz, 1984, Synthetic full waveform acoustic logs in cased borehole, Geophysics, 49, 1051-1059.

Winbow, G.A., 1991, Seismic sources in open and cased boreholes, Geophysics, 56, 1040-1050.

Zhu Zhenya, C.H. Cheng, and M.N. Toksöz, 1993, Propagation of flexural waves in an azimuthally anisotropic borehole model, SEG 63rd International Meeting Expanded Abstracts, 68-71. 


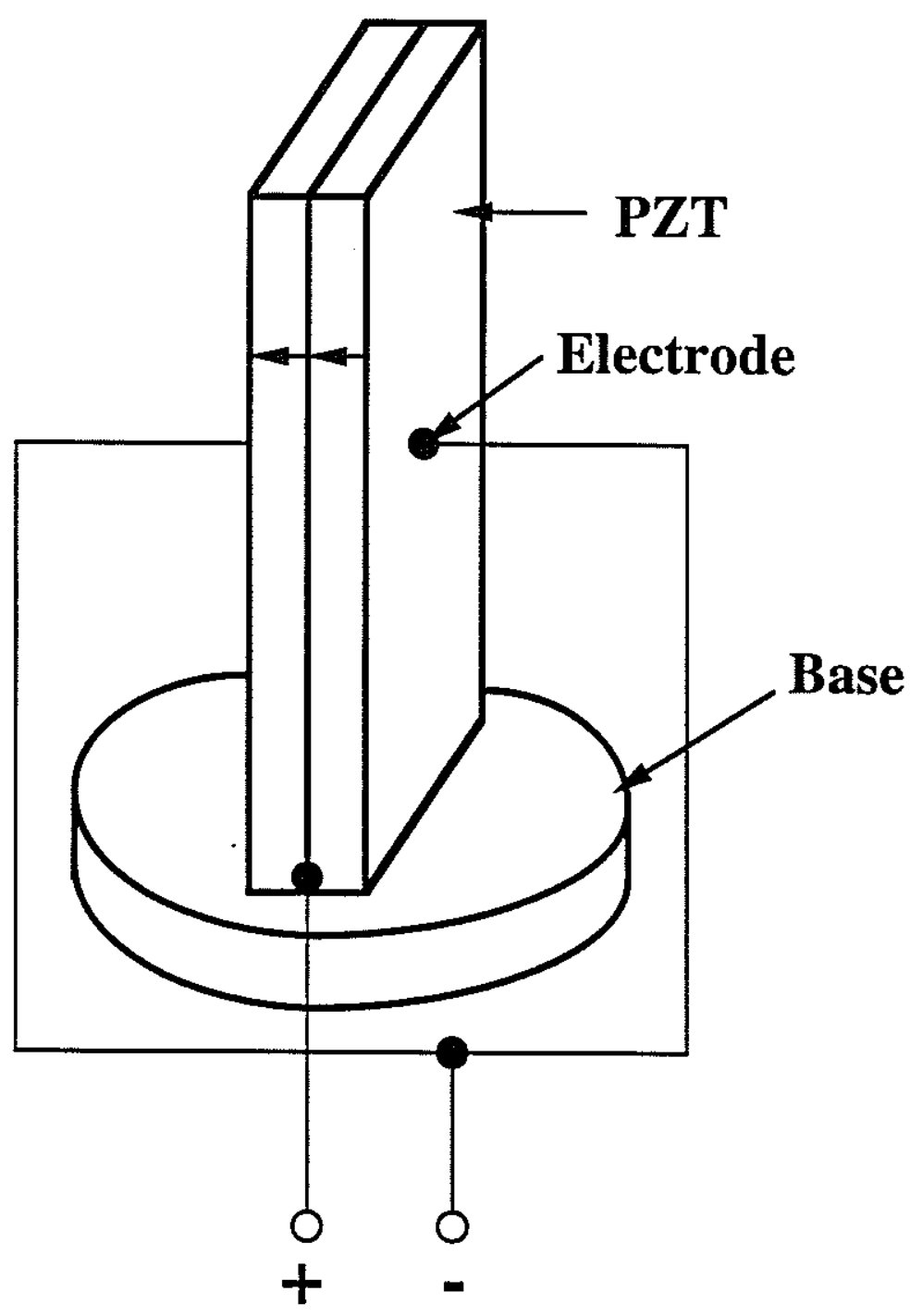

Figure 1: A diagram of a dipole transducer with bending vibration mode. 

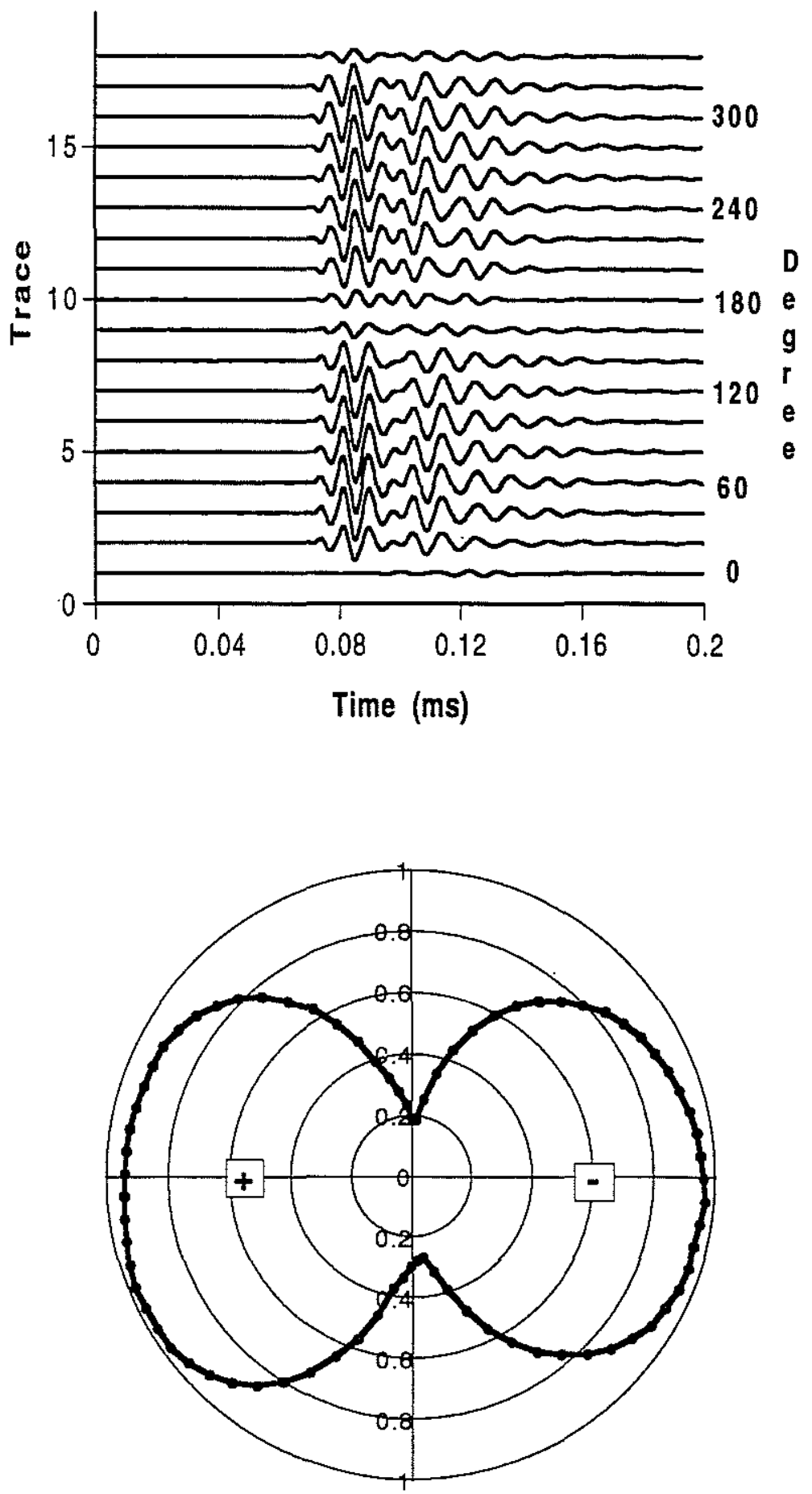

Figure 2: Waveforms received at various azimuths and the radiation pattern. 
(a)
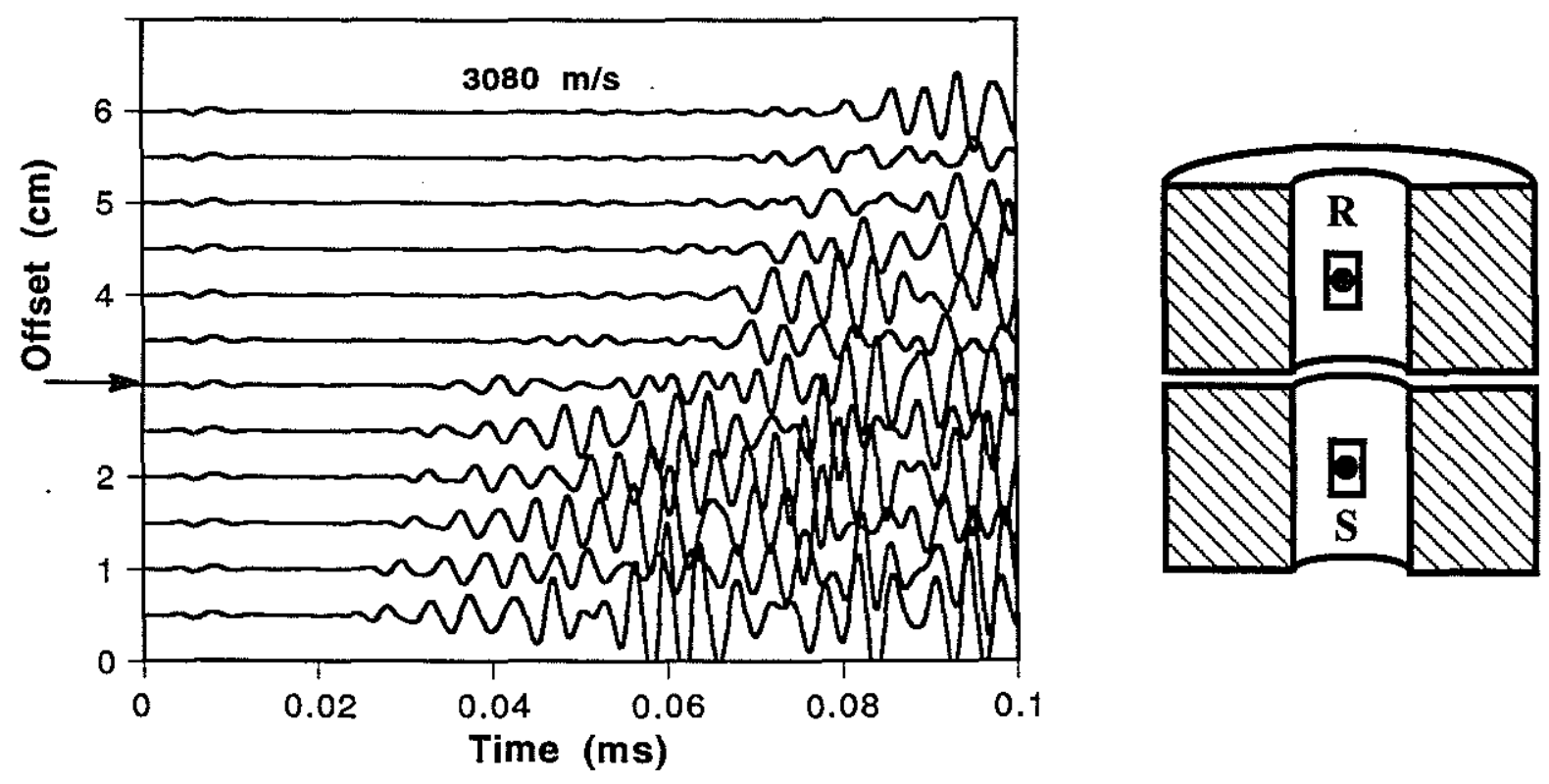

(b)
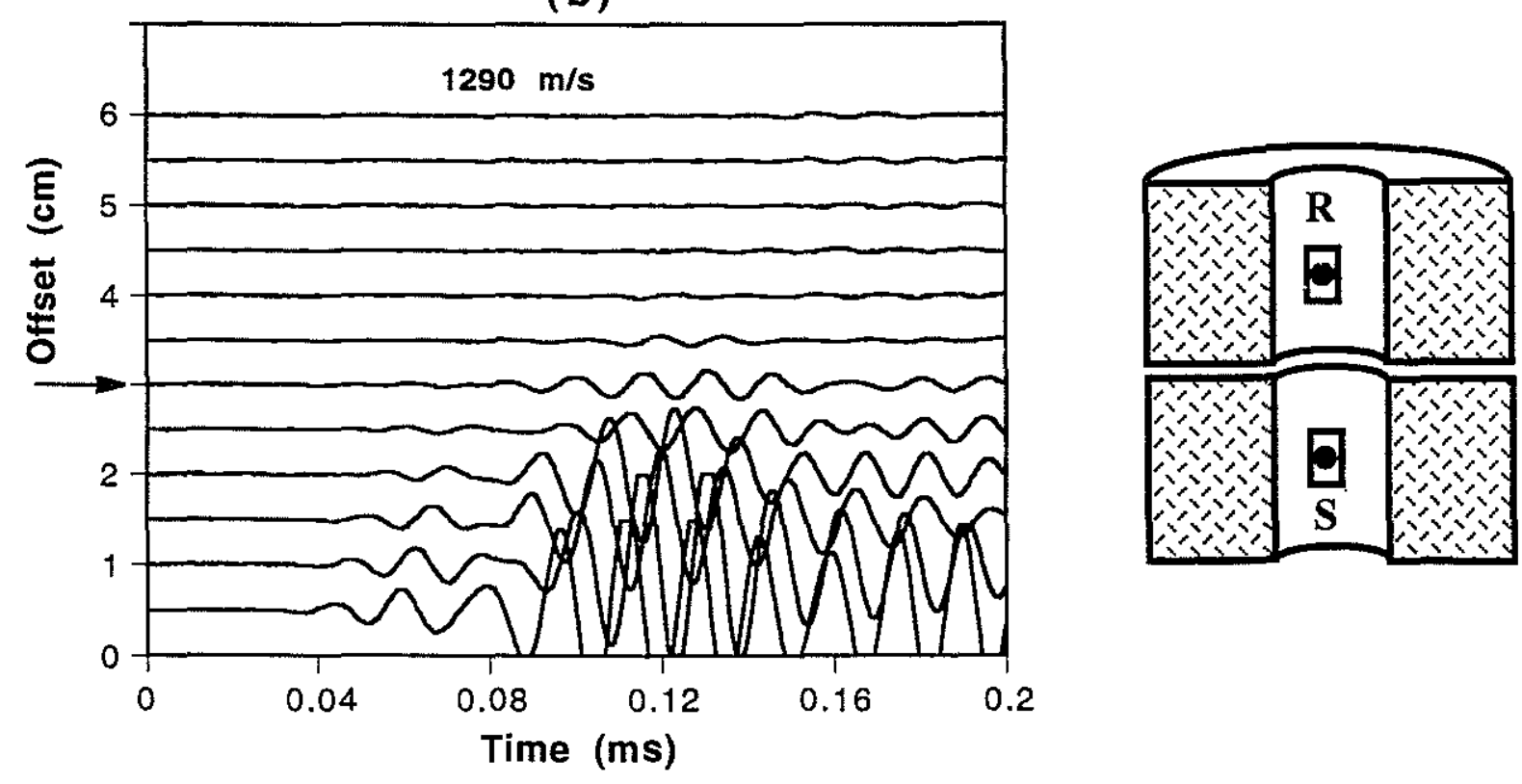

Figure 3: Flexural waveforms received in the aluminum (a) and lucite (b) borehole models with horizontal fractures. 


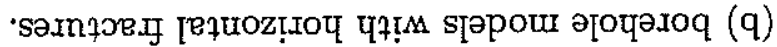

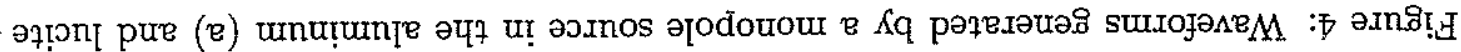

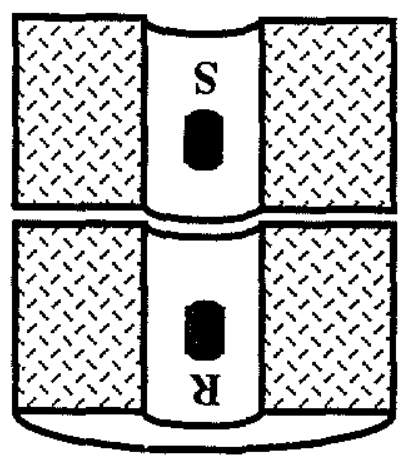

(su) әw!!

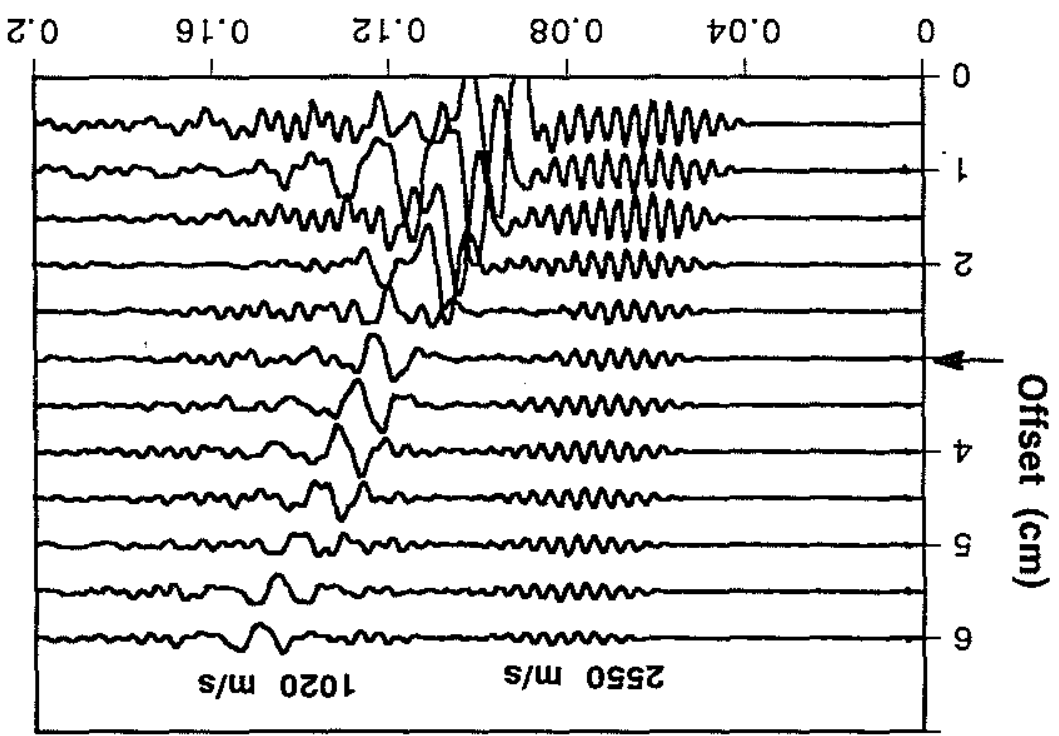

(q)
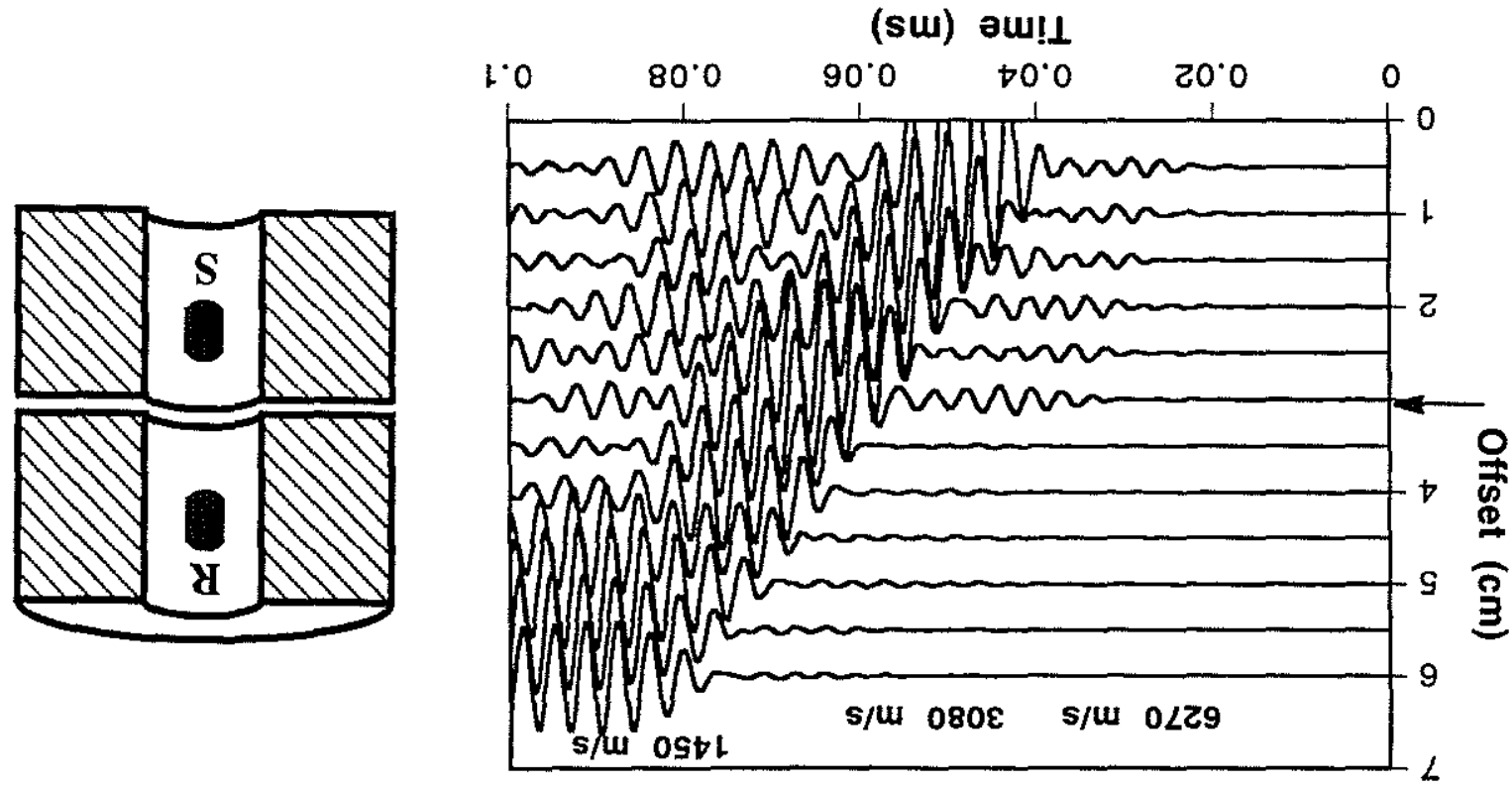

(e) 
(a)
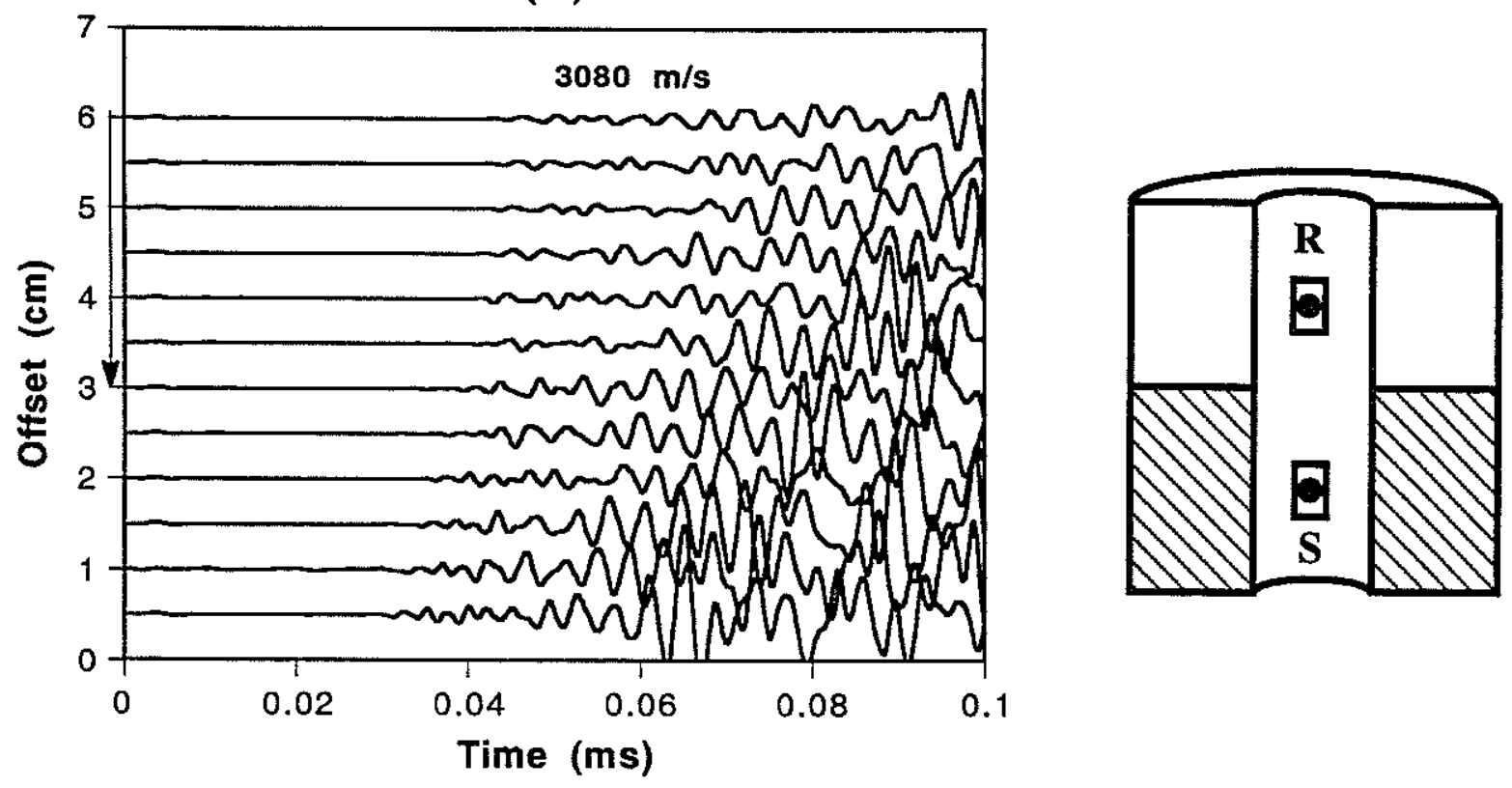

(b)
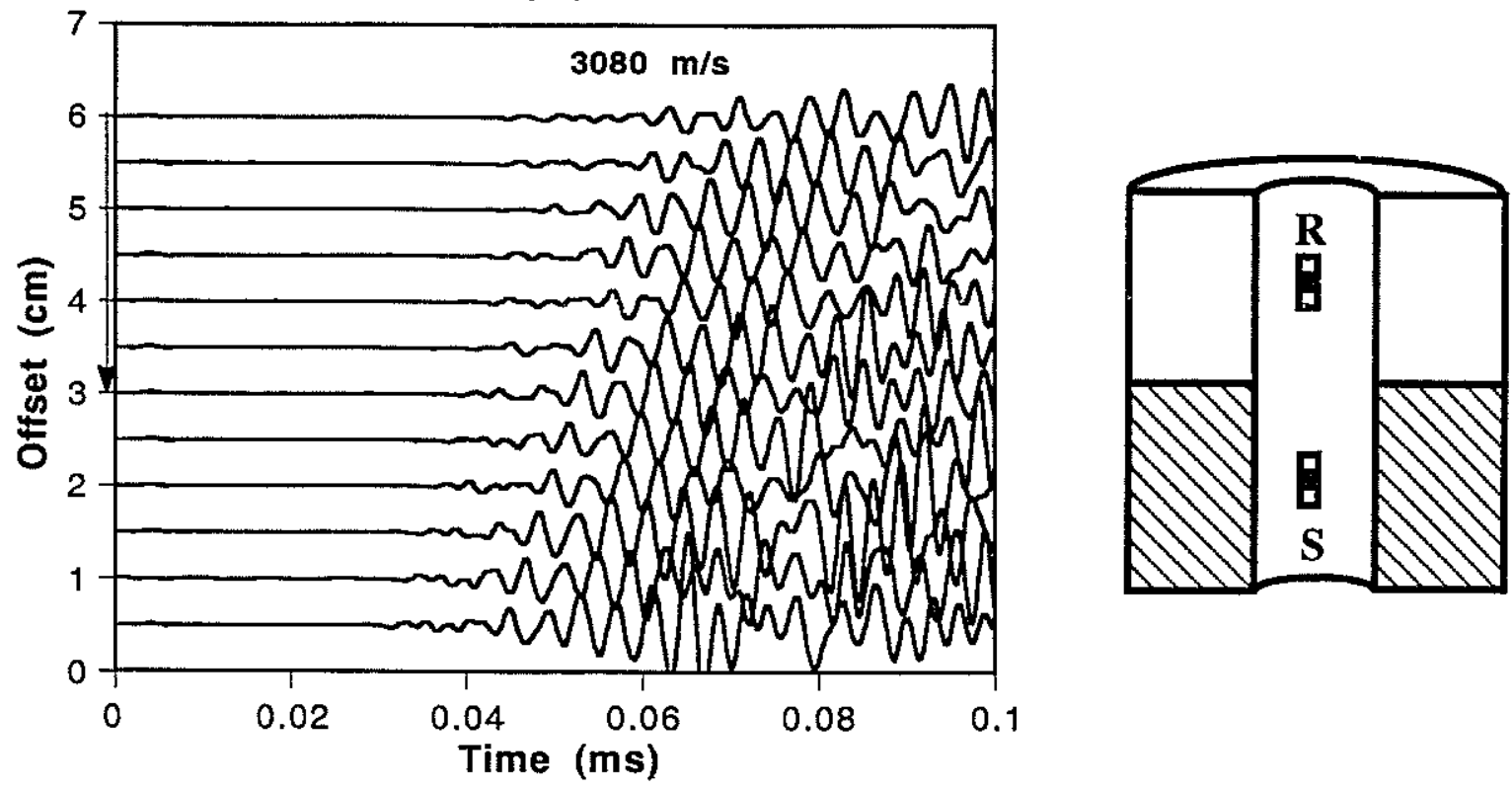

Figure 5: Flexural waveforms received in the aluminum borehole model with a vertical fracture: (a). the polarization of the dipole transducers and the normal direction of the fracture are in the same plane. (b). the polarization of the dipole transducers is perpendicular to the normal direction of the fracture. 
(a)
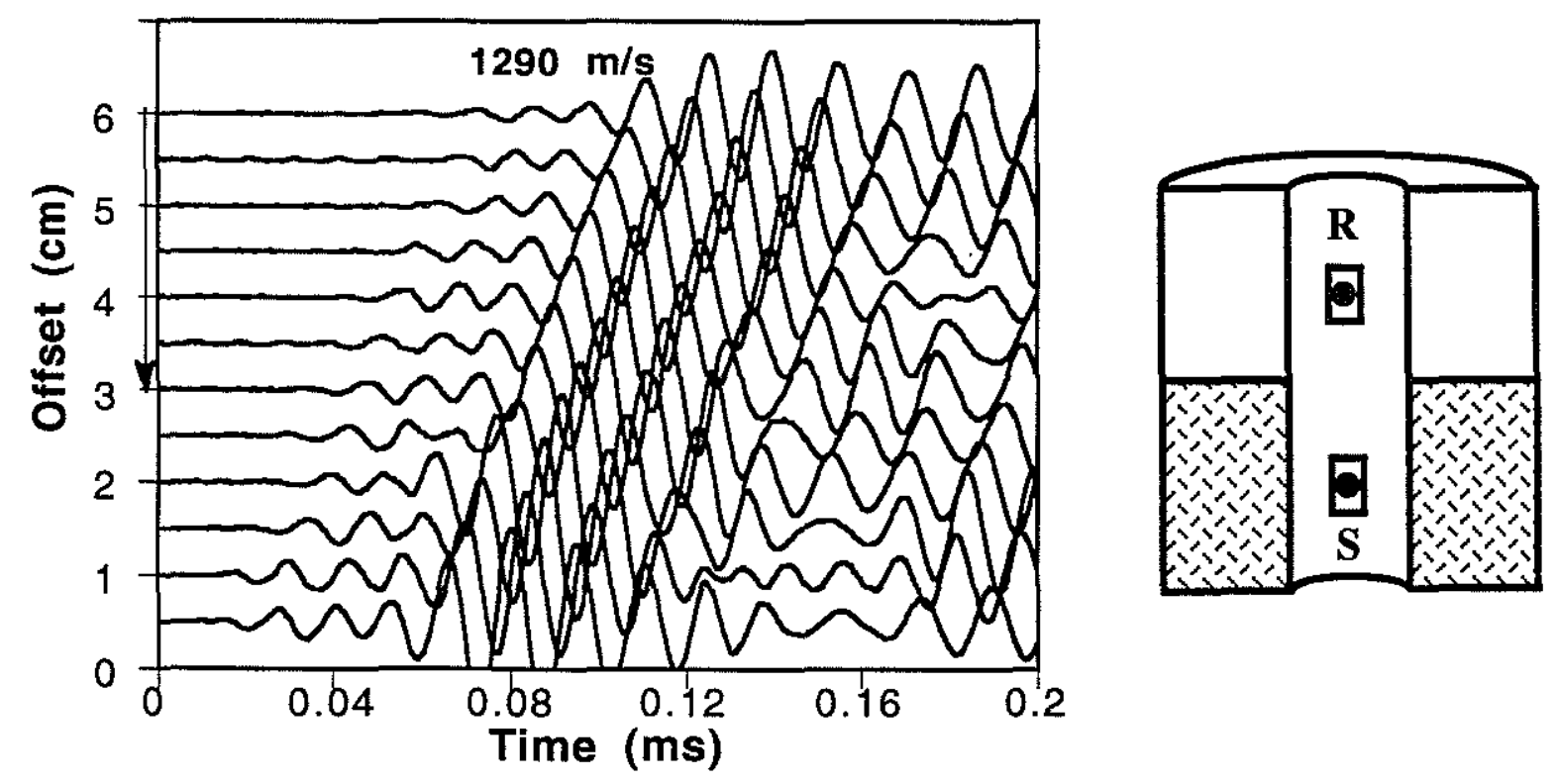

(b)
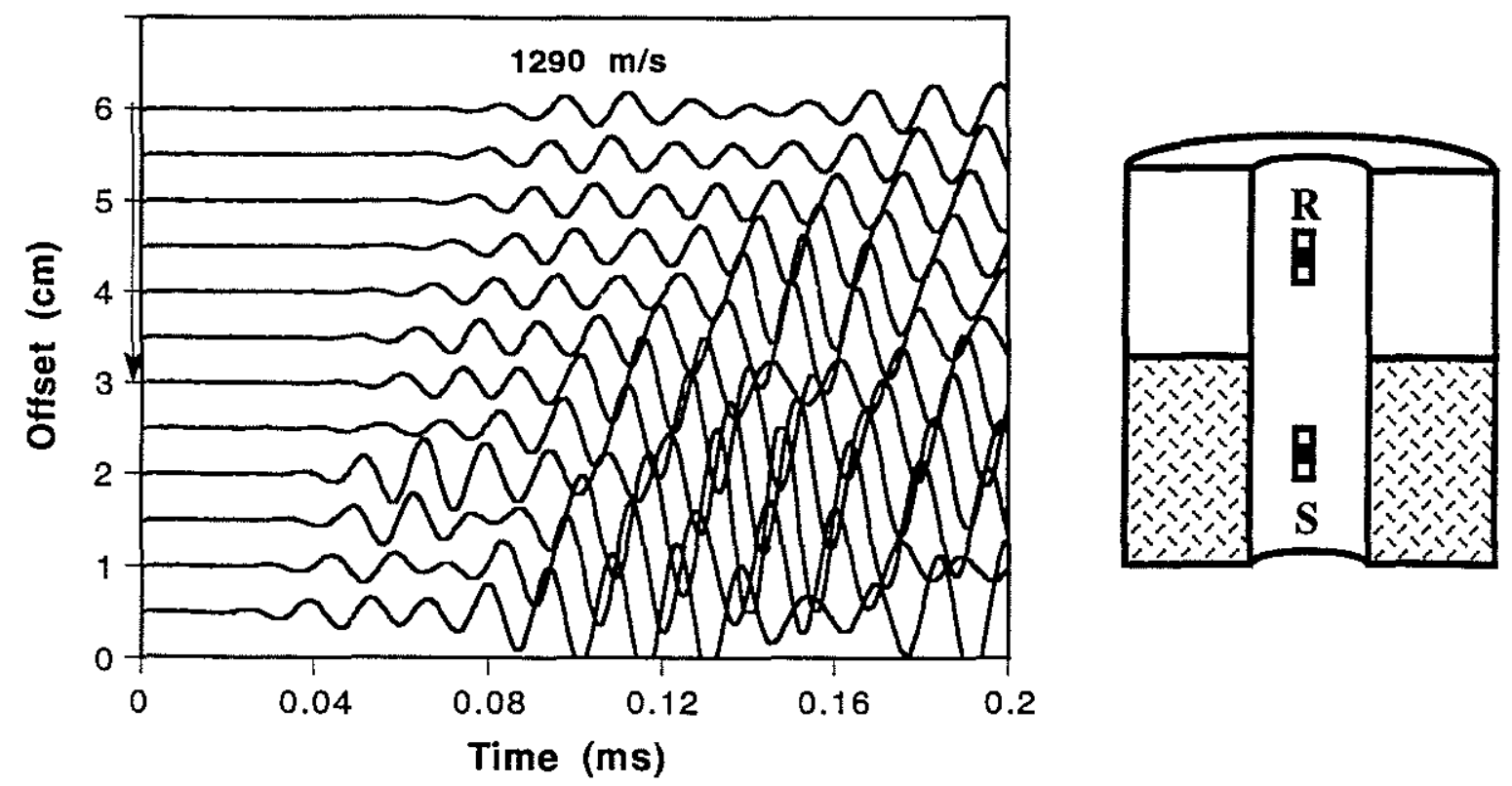

Figure 6: Flexural waveforms received in the lucite borehole model with a vertical fracture: (a). the polarization of the dipole transducers and the normal direction of the fracture are in the same plane. (b). the polarization of the dipole transducers is perpendicular to the normal direction of the fracture. 
(a)
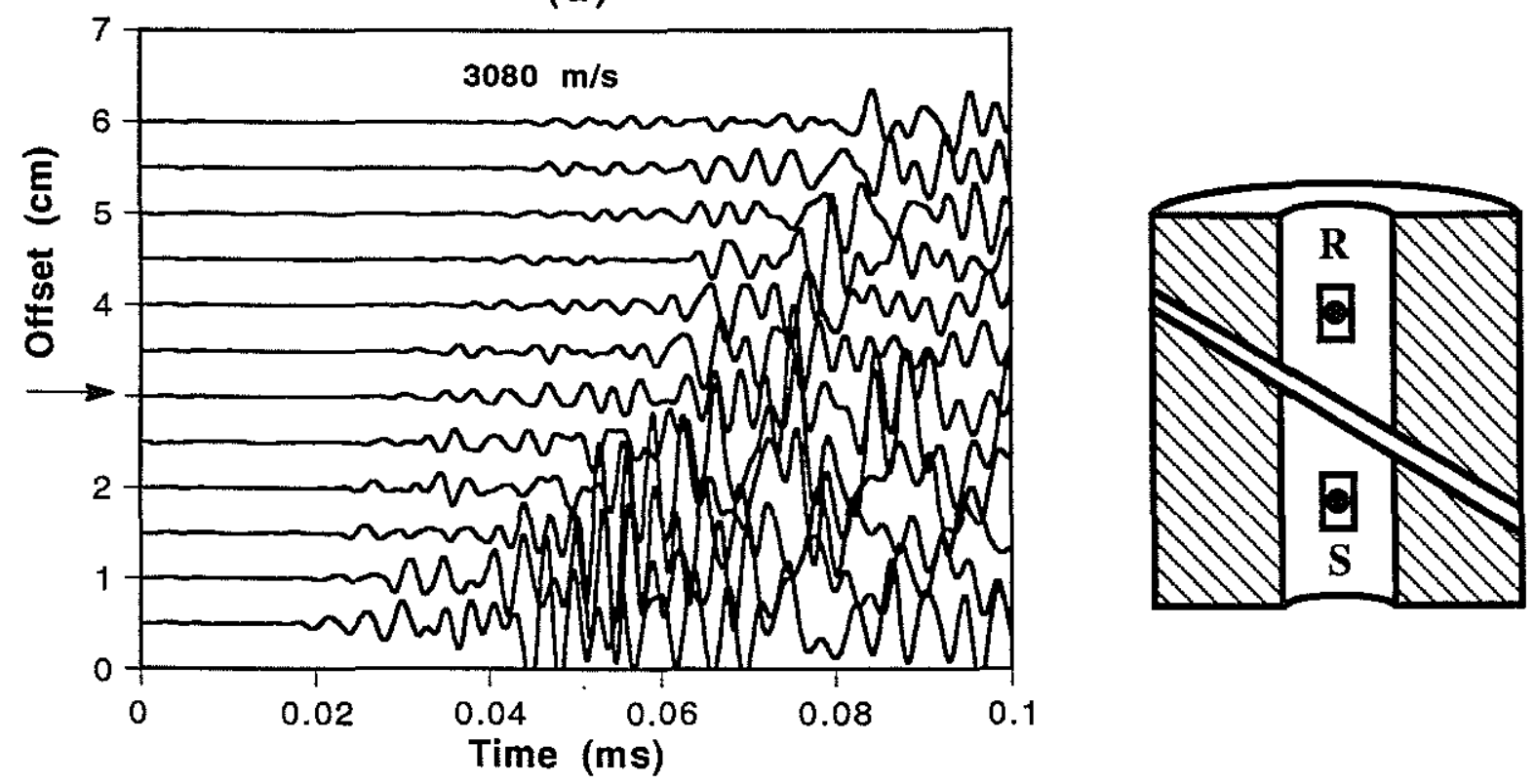

(b)
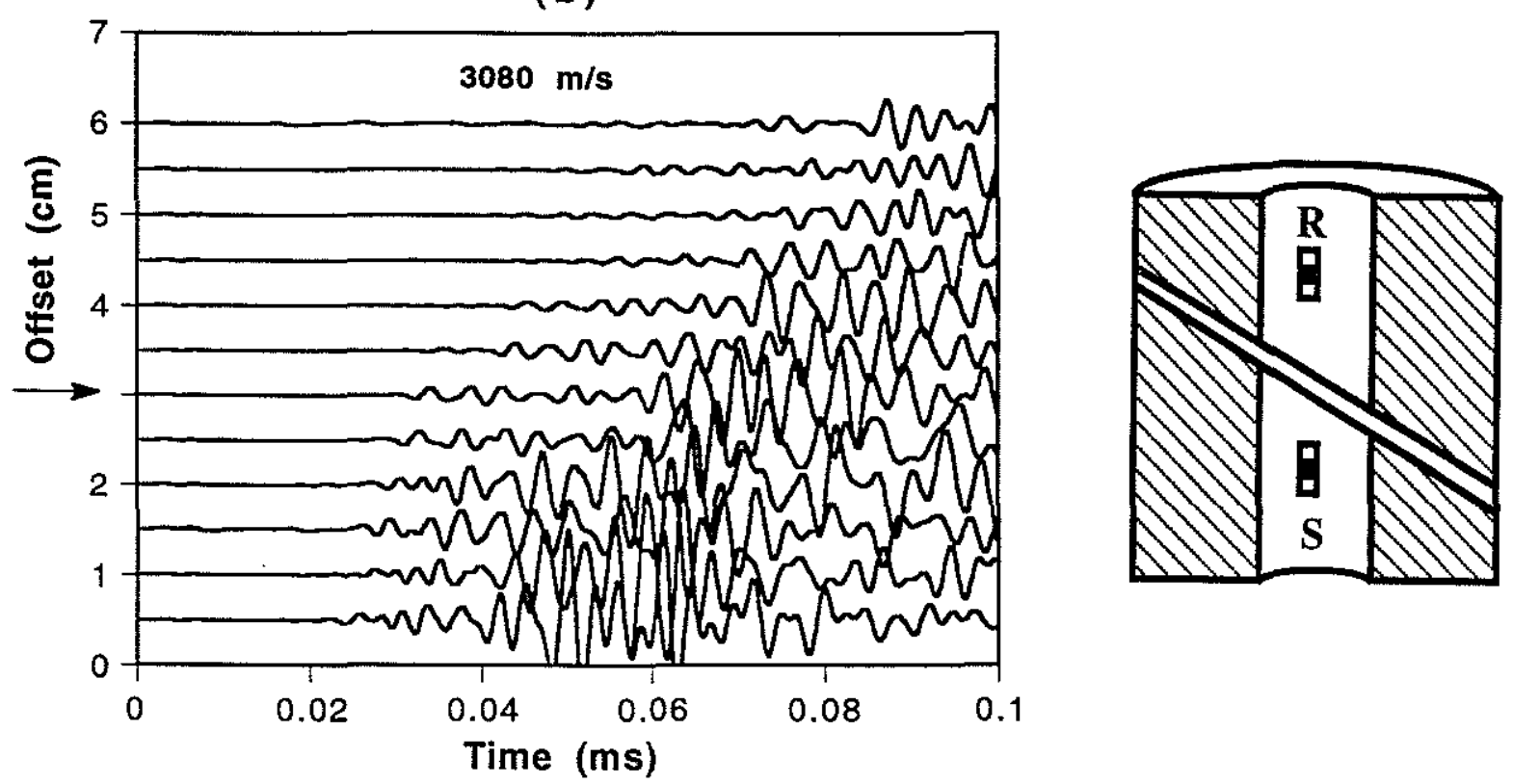

Figure 7: Flexural waveforms received in the borehole model with $45^{\circ}$-inclined fracture. (a). The polarization of the dipole transducers is perpendicular to the normal direction of the $45^{\circ}$-inclined fracture. (b). The polarization of the dipole transducers is in the same plane of the normal direction of the $45^{\circ}$-inclined fracture. 


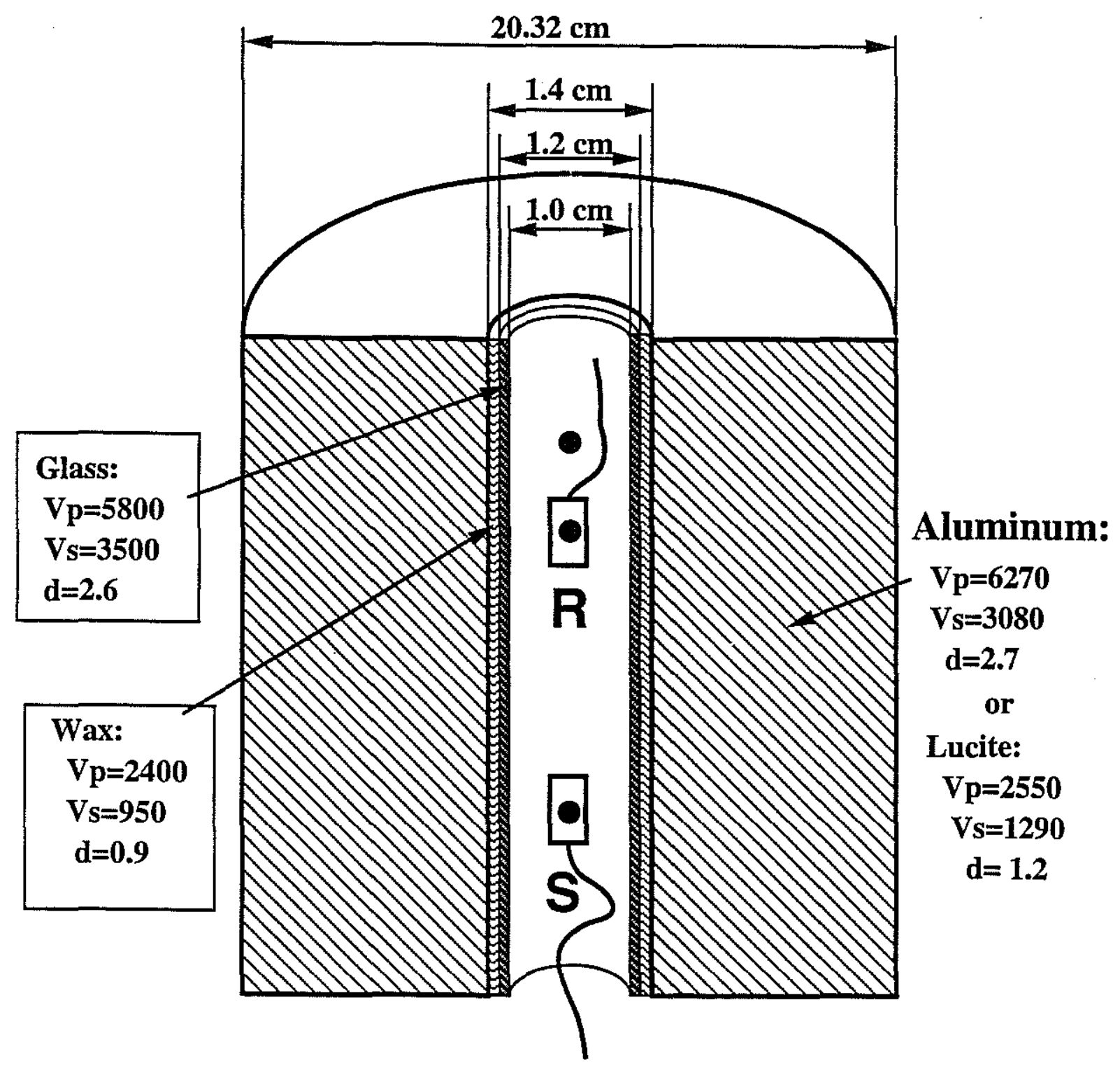

Figure 8: A cased borehole model. 

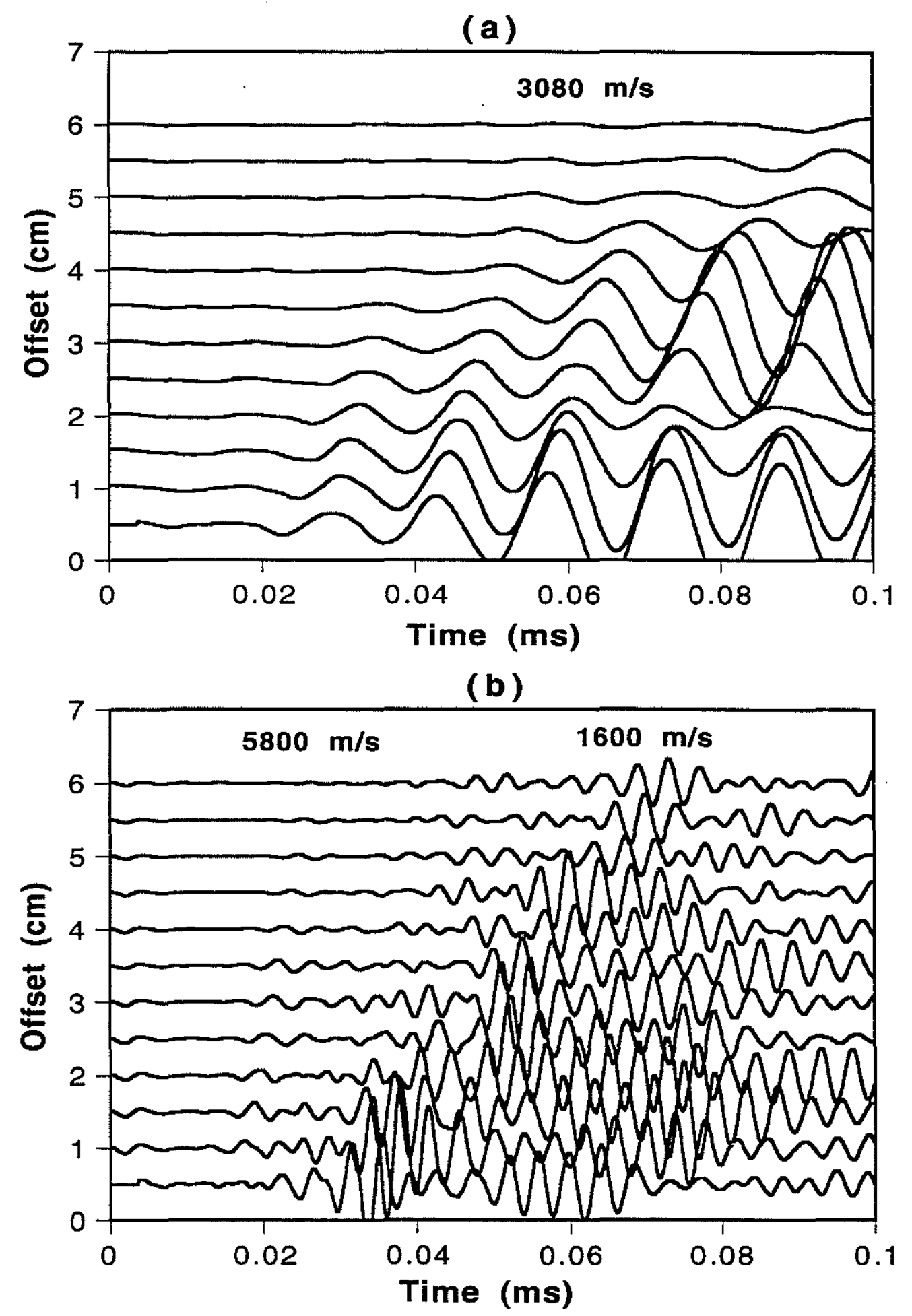

Figure 9: Waveforms generated by a dipole source in the aluminum cased borehole model at low (a) and high (b) frequencies. 


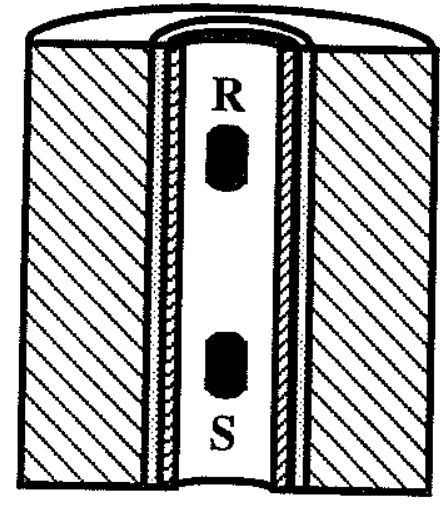

(b)

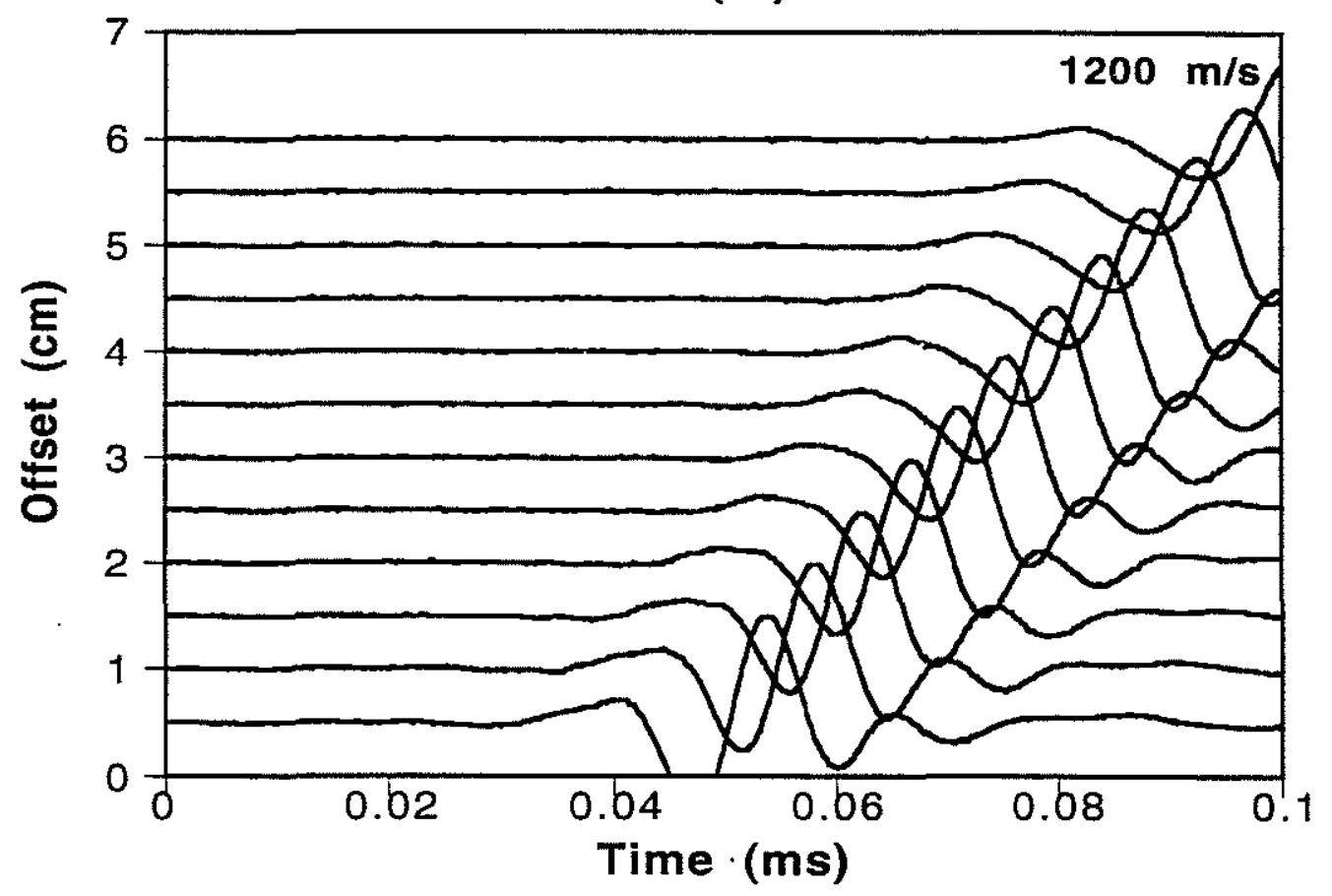

Figure 10: Low-frequency wave generated by a monopole source in the aluminum cased borehole model. 


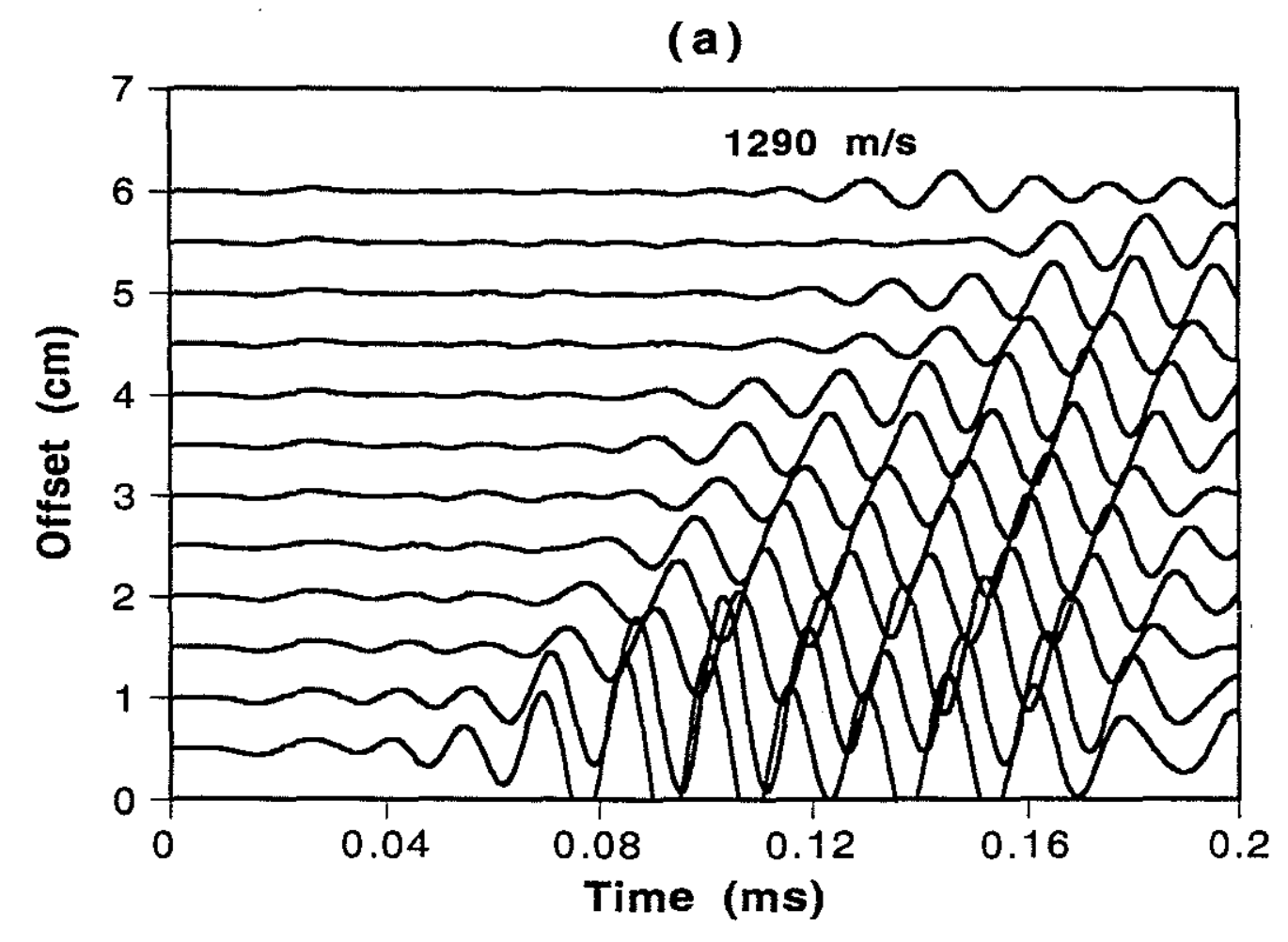

Figure 11: Waveforms generated by a dipole source in the lucite cased borehole model at low (a), medium (b), and high (c) frequencies. 
(b)
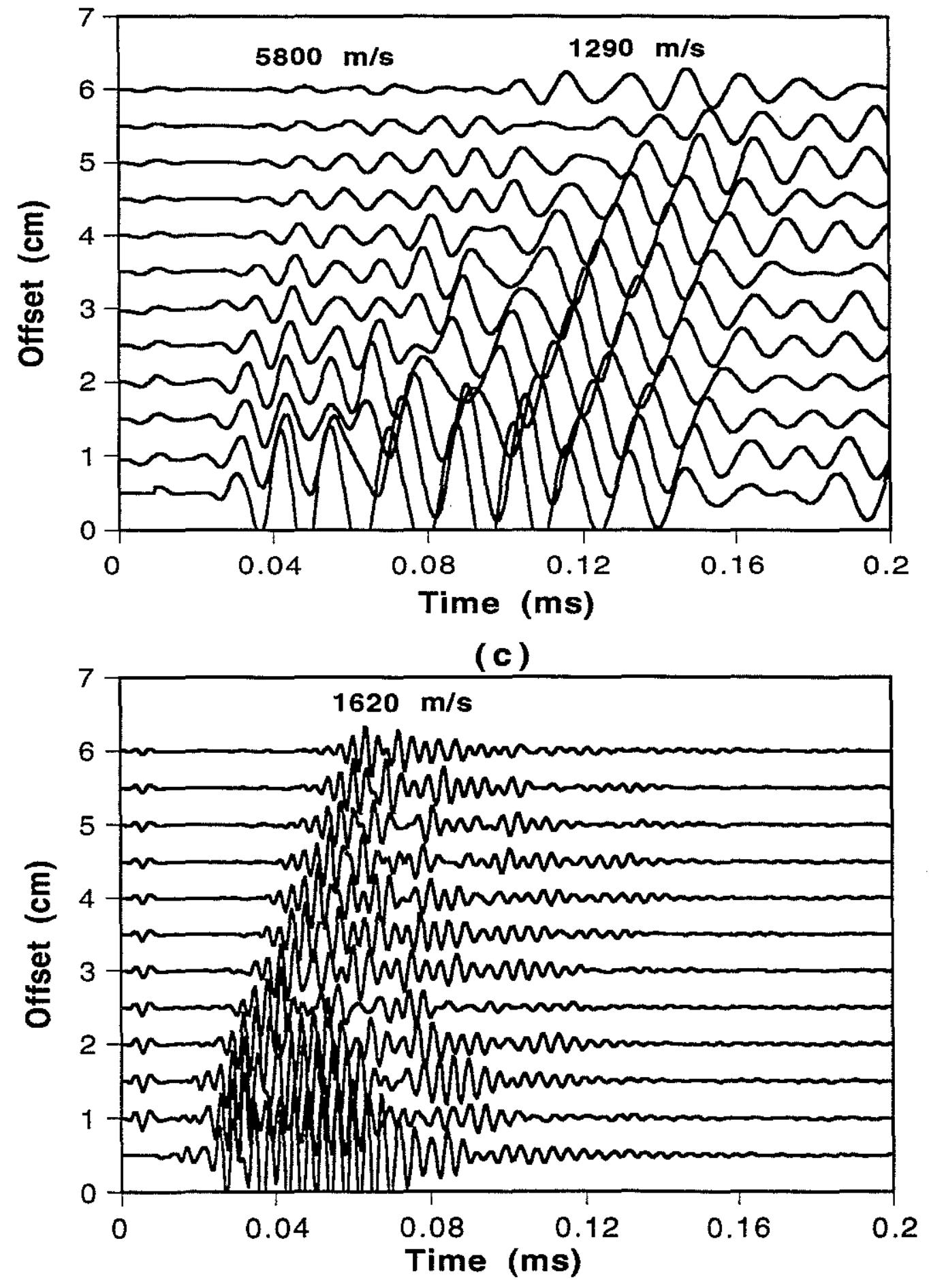


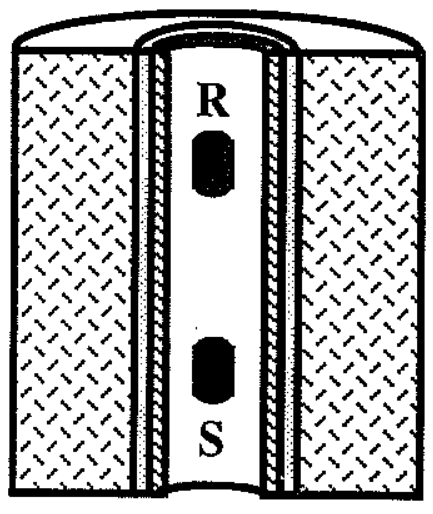

(b)

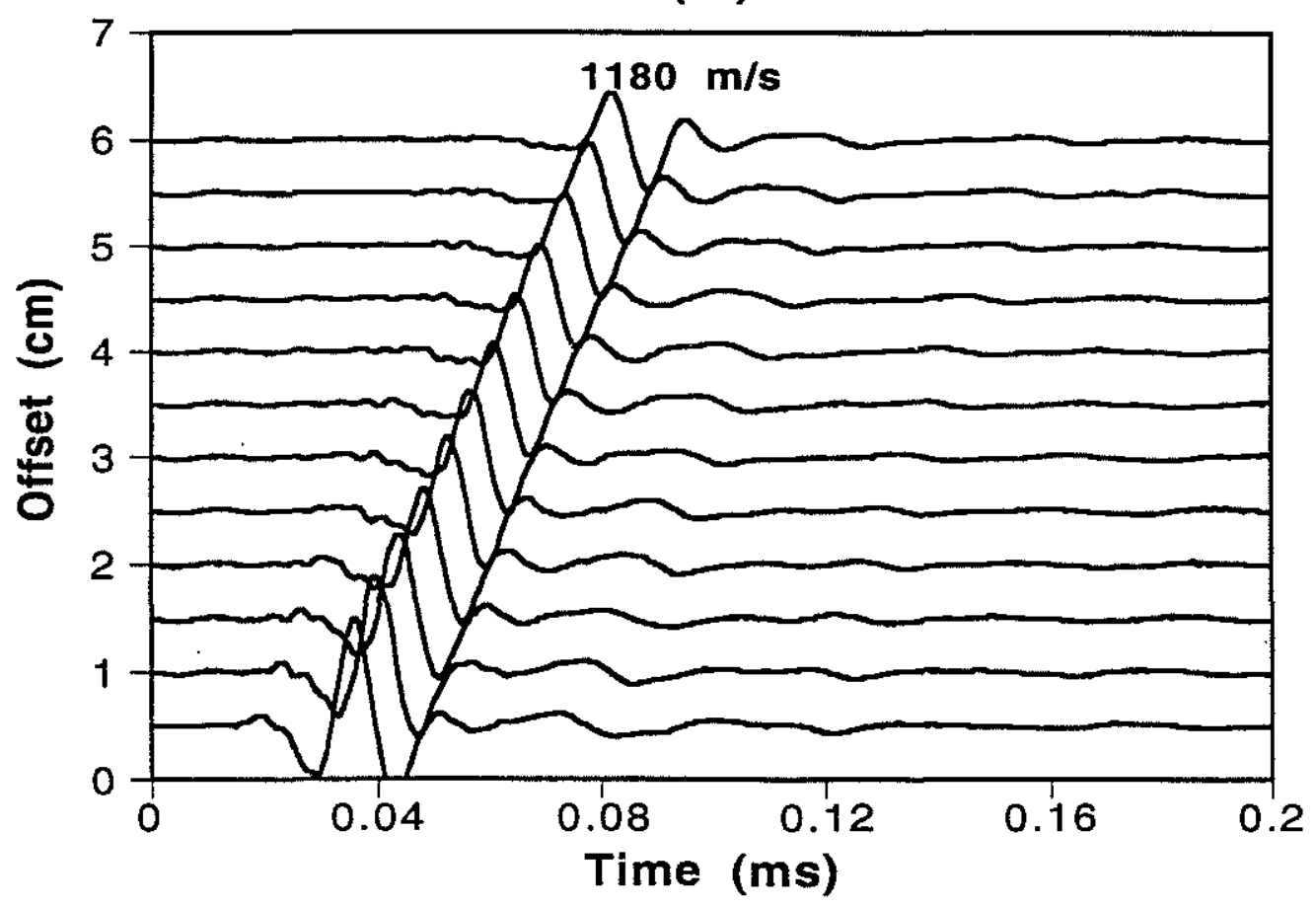

Figure 12: Low-frequency wave generated by a monopole source in the lucite cased borehole model 